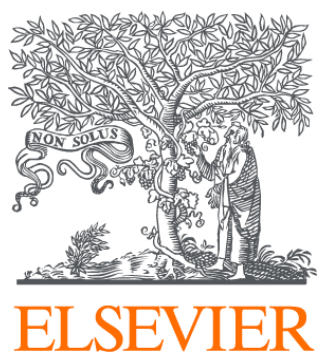

Since January 2020 Elsevier has created a COVID-19 resource centre with free information in English and Mandarin on the novel coronavirus COVID-

19. The COVID-19 resource centre is hosted on Elsevier Connect, the company's public news and information website.

Elsevier hereby grants permission to make all its COVID-19-related research that is available on the COVID-19 resource centre - including this research content - immediately available in PubMed Central and other publicly funded repositories, such as the WHO COVID database with rights for unrestricted research re-use and analyses in any form or by any means with acknowledgement of the original source. These permissions are granted for free by Elsevier for as long as the COVID-19 resource centre remains active. 


\section{FELINE IMMUNODEFICIENCY ABCD guidelines on prevention and management}

\author{
Margaret J Hosie, Diane Addie, Sándor Belák, Corine Boucraut-Baralon, \\ Herman Egberink, Tadeusz Frymus, Tim Gruffydd-Jones, Katrin Hartmann, \\ Albert Lloret, Hans Lutz, Fulvio Marsilio, Maria Grazia Pennisi, \\ Alan D Radford, Etienne Thiry, Uwe Truyen and Marian C Horzinek
}

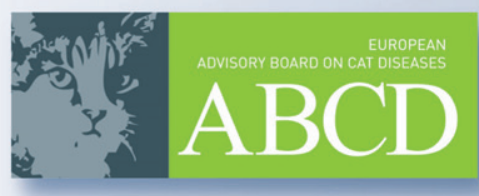

\section{Virus properties}

Feline immunodeficiency virus (FIV) is a retrovirus of the genus Lentivirus that is closely related to human immunodeficiency virus (HIV), sharing a similar structure, life cycle and pathogenesis. ${ }^{1}$ However, it is important to emphasise that humans are not susceptible to FIV infection. The FIVs are a large and ancient group of viruses; species-specific strains have been isolated from a variety of nondomestic felids, including the puma, lion, leopard and Pallas cat. ${ }^{2-5}$

Lentiviruses are complex retroviruses containing accessory genes in addition to gag, pol and env. The FIV gag gene encodes the capsid protein p24, which is important for diagnosis. The pol gene encodes protease, integrase and reverse transcriptase proteins as well as additional enzymes that are important to the virulence of FIV. Both gag and pol are relatively conserved between strains. The env gene encodes the viral glycoprotein (gp120) and the transmembrane protein (gp41), the major determinants of viral diversity among isolates. ${ }^{6}$

Five genetically distinct subtypes or clades (A to E) have been defined, with considerable sequence diversity (up to $26 \%$ ) in the env gene. ${ }^{7}$ Most viruses identified so far belong to either subtype A or B. Although multiple subtypes have been documented in cats from the same continent, geographic clustering is evident. This is important for PCR diagnosis. In the UK, only subtype A viruses are found. In other countries (eg, Switzerland, Australia, the western United States, northern Japan, Germany and South Africa) other clades are present, although subtype A viruses predominate. ${ }^{7-9}$ Subtype B viruses are also distributed worldwide but have been more consistently identified in eastern Japan, Italy,

Portugal, and the eastern United States.
European Advisory Board on Cat Diseases The European Advisory Board on Cat Diseases (ABCD) is a body of experts in immunology, vaccinology and clinical feline medicine that issues guidelines on prevention and management of feline infectious diseases in Europe, for the benefit of the health and welfare of cats. The guidelines are based on current scientific knowledge of the diseases and available vaccines concerned.

An extended version of the feline immunodeficiency guidelines presented in this article is available at www.abcd-vets.org
In contrast, subtype C viruses are less common (Fig 1).

The virus survives only minutes outside the host and is susceptible to all disinfectants including common soap.

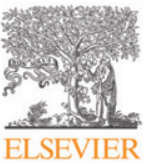
European Advisory Board on Cat Diseases www.abcd-vets.org Corresponding author: Margaret $\mathrm{J}$ Hosie Email:m.hosie@vet.gla.ac.uk

Overview Feline immunodeficiency virus (FIV) is a retrovirus closely related to human immunodeficiency virus. Most felids are susceptible to FIV, but humans are not. Feline immunodeficiency virus is endemic in domestic cat populations worldwide. The virus loses infectivity quickly outside the host and is susceptible to all disinfectants. Infection Feline immunodeficiency virus is transmitted via bites. The risk of transmission is low in households with socially well-adapted cats. Transmission from mother to kittens may occur, especially if the queen is undergoing an acute infection. Cats with FIV are persistently infected in spite of their ability to mount antibody and cell-mediated immune responses.

Disease signs Infected cats generally remain free of clinical signs for several years, and some cats never develop disease, depending on the infecting isolate. Most clinical signs are the consequence of immunodeficiency and secondary infection. Typical manifestations are chronic gingivostomatitis, chronic rhinitis, lymphadenopathy, weight loss and immune-mediated glomerulonephritis. Diagnosis Positive in-practice ELISA results obtained in a low-prevalence or low-risk population should always be confirmed by a laboratory. Western blot is the 'gold standard' laboratory test for FIV serology. PCR-based assays vary in performance.

Disease management Cats should never be euthanased solely on the basis of an FIV-positive test result. Cats infected with FIV may live as long as uninfected cats, with appropriate management. Asymptomatic FIV-infected cats should be neutered to avoid fighting and virus transmission. Infected cats should receive regular veterinary health checks. They can be housed in the same ward as other patients, but should be kept in individual cages.
Vaccination recommendations At present, there is no FIV vaccine commercially available in Europe. Potential benefits and risks of vaccinating FIV-infected cats should be assessed on an individual cat basis. Needles and surgical instruments used on FIV-positive cats may transmit the virus to other cats, so strict hygiene is essential.

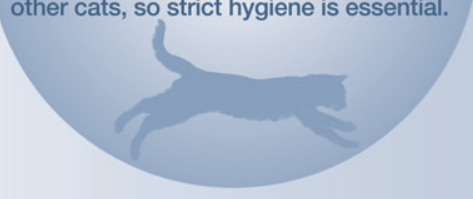




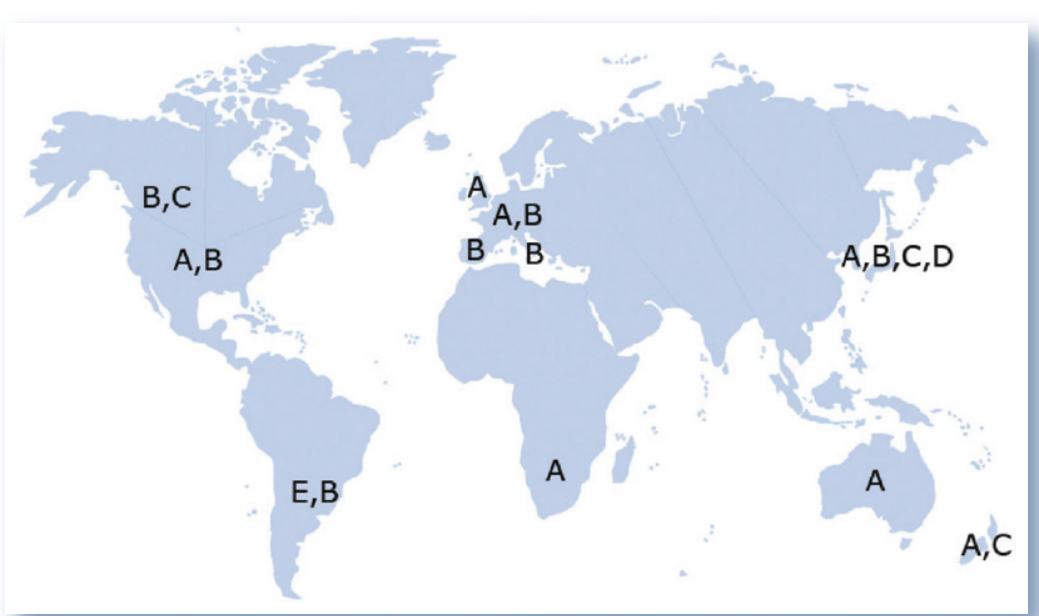

FIG 1 Global distribution of feline immunodeficiency virus subtypes or clades. Courtesy of Margaret $J$ Hosie

\section{If the queen is acutely infected, up to $70 \%$ of the kittens may become infected. If the seropositive queen is healthy, few kittens will be infected.}

\section{Epidemiology}

Since FIV was discovered in 1986, serological studies have demonstrated that it is endemic in domestic cat populations worldwide; the seroprevalence of FIV is highly variable between regions, with estimates of $1-14 \%$ in cats with no clinical signs and up to $44 \%$ in sick cats. ${ }^{10,11}$

Sick adult cats, male cats and free-roaming cats are most likely to be infected. ${ }^{12}$ The major route of natural transmission is via biting. ${ }^{13}$ Vertical transmission and transmission between cats in stable households is relatively uncommon.

Transmission from mother to kittens may occur but only some offspring become persistently infected, the proportion depending on the viral load of the queen during pregnancy and birth. If the queen is acutely infected, up to $70 \%$ of the kittens may become infected. If the seropositive queen is healthy, few kittens will be infected. ${ }^{14,15}$

Although neither oronasal nor venereal spread has been documented in nature, cats can be infected experimentally by virus inoculation into the nose, mouth, vagina and rectum, and virus can be recovered from semen after natural and experimental infection. ${ }^{16,17}$
Queens may be infected at mating if bitten by an infected tom cat.

\section{Pathogenesis}

The major targets for FIV infection are activated CD4+ T lymphocytes. These cells typically function as Thelper cells, which have a central role in immune function, facilitating the development of humoral and cell-mediated immunity. The FIV envelope glycoprotein gp120 binds to a primary receptor on the cell surface, the CD134 molecule. ${ }^{18,19}$ The viral reverse transcriptase that mediates transcription of the RNA genome into a DNA copy (or provirus) is error-prone and lacks a proofreading function; thus FIV mutates rapidly and displays great genetic diversity. Viral variants may evade immune detection and hamper the development of molecular diagnostic techniques and vaccines.

Infections become latent when a cell has integrated a provirus copy but does not produce virus particles - unless the cell becomes activated. Latently infected cells represent a 'reservoir' of infection that is not reached by neutralising antibodies, posing an obstacle for effective vaccination.

In the first few days after experimental infection, FIV replicates in dendritic cells, macrophages and CD4+ T lymphocytes, and within 2 weeks appears in the plasma. Both the virus levels in plasma and proviral DNA in the blood mononuclear cells increase, reaching a peak 8-12 weeks after infection. During this period, mild to moderate clinical signs such as anorexia, depression and fever may be observed. These conditions usually subside rapidly; in contrast, signs such as generalised lymphadenopathy, due to increased numbers and size of active germinal centres in the lymph nodes, may persist for weeks or months. The decrease in plasma viral load marks the beginning of the so-called 'asymptomatic' phase that can last for years (and may be lifelong). It is assumed that viral replication is controlled by the immune response, and during this phase the infected cat remains free of clinical signs.

The final outcome following FIV infection is variable. During the asymptomatic phase the plasma virus load is stable, but there is a progressive decline in $\mathrm{CD} 4+\mathrm{T}$ lymphocyte numbers, resulting in a decreased CD4:CD8 T lymphocyte ratio. ${ }^{20} \mathrm{In}$ a proportion of infected cats this leads to a functional immunodeficiency, clinical signs of acquired immunodeficiency syndrome (AIDS) and death.

Latently infected cells represent a 'reservoir' of infection that is not reached by neutralising antibodies, posing an obstacle for effective vaccination. 


\section{Immunity}

\section{Passive immunity}

In natural infections, the efficacy of colostral immunity is not known. Experimentally, susceptible kittens have been protected after passive transfer of antibody in response to challenge with laboratory-adapted isolates of FIV. ${ }^{21}$ However, this may not apply to challenge with virulent field strains, and indeed enhanced infection was seen after transfer of antibodies from cats immunised with an experimental vaccine, indicating a fine balance between neutralising and infectionenhancing antibodies. ${ }^{22}$

\section{Active immune response}

Cats infected with FIV remain persistently infected despite mounting antibody and cellmediated immune responses. Feline immunodeficiency virusspecific CD8+ cytotoxic T cells are detected in the blood within 1 week of infection. ${ }^{23}$ Coincident with the peak of viraemia, antiFIV antibodies, including virus neutralising antibodies, appear in the plasma. ${ }^{24}$ They generally appear from 2-4 weeks after infection, but seroconversion may be delayed in cats exposed to low virus doses. ${ }^{25}$ Antibodies recognising Env appear earlier than those against the Gag protein p24. ${ }^{26}$

\section{Clinical signs}

Most clinical signs are not directly caused by FIV, so it is vital to check for the underlying cause of the presenting clinical signs. In many cases, clinical signs will be the result of a secondary infection that should be identified and treated (see later). The virus itself is responsible for immunodeficiency (making the cat more susceptible to secondary infections and neoplasia) or immune stimulation (resulting in immune-mediated disease). In rare cases, FIV can cause neurological disease.

In the first weeks to months after infection, clinical signs lasting for a few days to a few weeks may be seen. These may include mild fever, lethargy and peripheral lymphadenopathy. ${ }^{27}$ Haematology may reveal a neutropenia. ${ }^{28}$

Infected cats then generally remain healthy before problems associated with immunodeficiency develop; ${ }^{29}$ this asymptomatic period will last for years in most cases, and some cats will never develop FIV-related clinical signs. ${ }^{30}$

\section{Most clinical signs are not directly caused by FIV,} so it is vital to check for the underlying cause of the presenting clinical signs.

Disease is often not seen until later in life generally 4-6 years of age or older.

Immunodeficiency and/or immunostimulation most frequently appear in the form of chronic gingivostomatitis, chronic rhinitis, lymphadenopathy, immune-mediated glomerulonephritis and weight loss (Fig 2).

Many concurrent viral, bacterial, fungal and protozoal infections have been reported in FIV-infected cats. $^{31,32}$ Unusual or severe parasitic skin disease (eg, demodicosis, pediculosis) or tumours should alert the clinician to the possibility of FIV infection. Various neoplastic conditions, such as B cell lymphosarcomas, myeloproliferative disease and squamous cell carcinoma, have been reported in association with FIV infection. ${ }^{33}$

Chronic gingivostomatitis is one of the most common presenting signs in FIV-infected cats, and impairs the cat's quality of life (Fig 3)..$^{34}$

As confirmed by experimental infections with neurovirulent strains, central nervous system involvement and peripheral neuropathy are early subclinical events, often associated only with altered forebrain or peripheral nerve electrical activity. ${ }^{35,36}$ Behavioural changes, seizures,

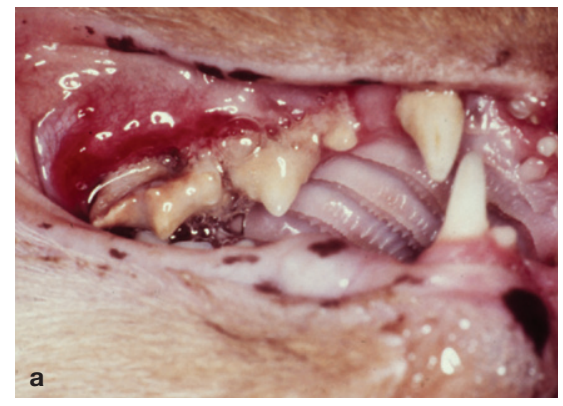

FIG 3 (a) Severe periodontal disease and (b) chronic gingivostomatitis are common signs in cats with feline immunodeficiency virus infection. Courtesy of (a) Andy Sparkes; (b) Albert Lloret

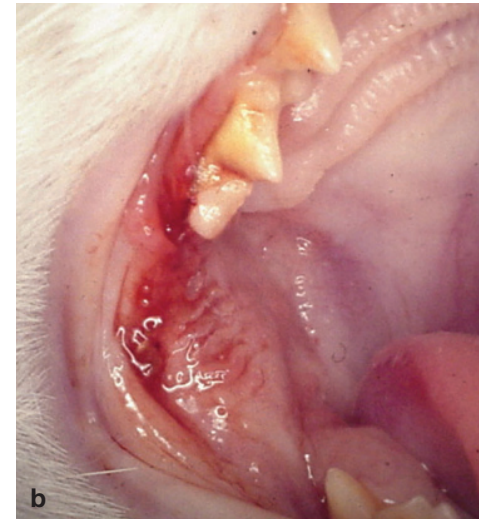




\section{The asymptomatic period will last for years in most cases,} and some cats will never develop FIV-related clinical signs. Disease is often not seen until later in life - generally 4-6 years of age or older.

disrupted sleep patterns, impaired learning and paresis have also been reported. ${ }^{37}$

Reproductive failure occurs in infected cats and is associated with PCR-positive placental and fetal tissues. ${ }^{38}$ Renal involvement arising from glomerular and tubulointerstitial lesions associated with severe proteinuria is frequent in FIV-infected cats. Renal damage is caused possibly by the virus, together with renal immune deposits. ${ }^{39}$ Polyclonal B cell activation sustains hyperglobulinaemia and high levels of circulating immune complexes and autoantibodies. ${ }^{40,41}$

\section{Diagnosis}

\section{Direct detection methods}

* Virus isolation Virus isolation is a reliable diagnostic method but is laborious and not used routinely. Peripheral blood lymphocytes from fresh heparinised blood samples are co-cultivated with primary feline T cells for 2-3 weeks, and the presence of virus is confirmed by measuring the levels of viral core proteins in the culture fluids.

* Polymerase chain reaction Assays that detect proviral DNA are available, but vary in performance and may be inferior to serological tests, with sensitivities and specificities ranging from $40-100 \%$ [EBM grade I]. ${ }^{42}$ Current PCR assays detect clade A viruses well, but the other clades more variably. Strain variation may also explain discrepant results when identical samples are sent to different laboratories. ${ }^{43}$

\section{Indirect detection methods}

* Antibody detection Routine tests for FIV infection detect antibodies recognising viral structural proteins (such as the capsid protein p24 and a gp41 peptide) and may take the form of ELISA and immunochromatography tests. Western blot analysis is considered the 'gold standard' for FIV serology and is used to confirm inconclusive results. In-house ELISAs are based on detecting antibodies recognising p24

\section{EBM ranking used in this article}

Evidence-based medicine (EBM) is a process of clinical decision-making that allows clinicians to find, appraise and integrate the current best evidence with individual clinical expertise, client wishes and patient needs (see Editorial on page 529 of this special issue, doi:10.1016/j.jfms.2009.05.001).

This article uses EBM ranking to grade the level of evidence of statements in relevant sections on diagnosis, disease management and control as well as vaccination. Statements are graded on a scale of I to IV as follows:

- EBM grade I This is the best evidence, comprising data obtained from properly designed, randomised controlled clinical trials in the target species (in this context cats);

- EBM grade II Data obtained from properly designed, randomised controlled studies in the target species with spontaneous disease in an experimental setting;

* EBM grade III Data based on non-randomised clinical trials, multiple case series, other experimental studies, and dramatic results from uncontrolled studies;

H EBM grade IV Expert opinion, case reports, studies in other species, pathophysiological justification. If no grade is specified, the EBM level is grade IV.

\section{Further reading}

Roudebush P, Allen TA, Dodd CE, Novotny BJ. Application of evidence-based medicine to veterinary clinical nutrition. J Am Vet Med Assoc 2004; 224: 1765-71. and the transmembrane protein (communication from Idexx, March 2008). In contrast, immunochromatography tests detect only antibodies recognising short peptides from the transmembrane protein. In Western blots, purified FIV is first separated by gel electrophoresis into its constituent proteins, and the individual FIV proteins are detected by antibodies. ${ }^{45}$

Both ELISA and immunochromatography tests are generally appropriate, but have limitations (see box on page 579).

+ CD4+ and CD8+ lymphocytes It is possible to stage the level of immune dysfunction by determining the CD4+ and CD8+ lymphocyte counts. However, due to the complexity of these assays, and the fact that in a clinical situation pre-infection values are not available, these tests are not clinically useful. 


\section{Management of FIV-infected cats}

\author{
General management \\ * Isolation One of the most important \\ preventive health measures is to protect \\ an FIV-infected cat from other infections. \\ These may not only cause clinical signs \\ but may also lead to progression of the FIV \\ infection itself. Confining the cat indoors \\ will minimise this risk and avoid potential \\ transmission of FIV to other cats. In \\ multi-cat households with other endemic \\ infectious disease problems, any \\ FIV-infected cats should be kept separate.
}

- Neutering Healthy seropositive cats should be neutered, as it may reduce aggression in tom cats and thereby the associated risk of FIV transmission. Neutering will also help to reduce roaming and contact with neighbouring cats.

* Frequent health checks Cats infected with FIV should be examined clinically at least every 6 months and monitored for weight loss. Periodic routine laboratory testing (haematology, biochemistry, urinalysis) should be considered.

* Perioperative precautions Surgery is generally well tolerated by asymptomatic FIV-infected cats, but perioperative antibiotic administration should accompany all surgical and dental procedures. Cats that are infected with FIV should be considered immune-deficient and isolated from cats with other infectious diseases. Although seropositive cats can be housed in the same ward as other hospitalised patients, they should be kept in individual cages, and not in a 'contagious ward' with cats suffering from infections such as viral respiratory disease.

* Routine vaccination Routine vaccination of FIV-seropositive cats is a controversial subject. Asymptomatic FIV-infected cats in the early stages of infection develop a strong immune response after vaccination, as good as may be expected in noninfected cats. However, it is unknown whether cats in the later stages, and those showing immunodeficiency, develop an adequate response to vaccination. Safety concerns have been raised about the routine vaccination of FIV-infected cats. Immune stimulation caused by the vaccine may lead to disease progression, since stimulation of FIV-infected lymphocytes in vitro is known to promote virus production. Vaccination of chronically infected FIV-infected cats with a synthetic peptide was associated with a decrease in the CD4:CD8 ratios. Hence, the risks and benefits of vaccinating FIV-infected cats should be weighed up on a case-by-case basis. For example, as the risk of infection is low for elderly indoor cats that have been vaccinated previously, booster vaccinations are best avoided, whereas booster vaccinations for outdoor cats are strongly advised. Although there is no scientific evidence that FIV-infected cats are at increased risk from modified-live virus vaccines, inactivated preparations are recommended, as attenuated virus may revert to virulence and cause disease in immunosuppressed cats. 


\section{Supportive treatment}

If FIV-infected cats are sick, prompt and accurate diagnosis is important to allow early intervention. Many respond well to appropri-

ate medication, although a longer or more

aggressive course of therapy (eg, with antibiotics) may be needed than in uninfected cats.

Some clinicians report benefits with corticosteroids and other immunosuppressive drugs in FIVinfected cats with chronic stomatitis, but their use is controversial because of side effects. Griseofulvin has caused bone marrow suppression and should not be used. ${ }^{51}$ Filgastrim (granulocyte colony-stimulation factor), a recombinant human cytokine (rHuG-CSF), has been used in cats with profound neutropenia. It can increase neutrophil counts, but may also lead to an increase in virus load [EBM grade III]. ${ }^{52,53}$

Erythropoietin is available as the recombinant human product and is used effectively in cats with non-regenerative anaemia due to endogenous erythropoietin deficiency in chronic renal failure. Cats with FIV treated with human erythropoietin (100 IU/kg SC q48h) showed a gradual increase in red and white blood cell counts [EBM grade IV] ${ }^{53}$ No increase in virus loads was observed, indicating that human erythropoietin can be used safely.

Insulin-like growth factor-1 is marketed as a recombinant human product and induces thymic growth and stimulates $\mathrm{T}$ cell function. Treatment resulted in a significant increase in thymus size and thymic cortical regeneration, replenishing the peripheral $\mathrm{T}$ cell pool in experimentally FIV-infected cats [EBM grade III]. ${ }^{54}$ It could be considered in young FIVinfected cats, but there have been no studies to demonstrate efficacy in field cases.

\section{Antiviral therapy}

Most of the antiviral drugs that are discussed here are licensed for treating HIV infection in humans. Unfortunately, many of the antivirals used in humans are toxic to cats or ineffective.

\section{AZT}

AZT (3'-azido-2', 3'-dideoxythymidine) is a nucleoside analogue (thymidine derivative) that blocks the retroviral reverse transcriptase. AZT inhibits FIV replication in vitro and in vivo; it can reduce plasma virus load, enhance cats' immunological and clinical status, and improve quality of life. In a placebo-controlled trial, AZT improved stomatitis in naturally infected cats [EBM grade I]. ${ }^{55}$ The appropriate dosage is $5-10 \mathrm{mg} / \mathrm{kg} \mathrm{q} 12 \mathrm{~h} \mathrm{PO}$ or SC. The higher dose should be used carefully as side effects can develop. For SC injection, the lyophilised product should be diluted in isotonic sodium chloride solution to prevent local irritation. For PO application, syrup or gelatine capsules (dosage/weight calculated individually for each cat) can be given.

During treatment, a complete blood count should be performed weekly for the first month, because non-regenerative anaemia is common, especially at higher doses. If the values are stable, monthly checks are sufficient. Cats with bone marrow suppression should not be treated. Studies of FIV-infected cats treated for 2 years showed that AZT is well tolerated. Some cats may develop a mild decrease in haematocrit in the first 3 weeks, which resolves even if treatment is continued. If haematocrit drops below 20\%, treatment should be discontinued, and anaemia then usually resolves within a few days. As in HIV, AZT-resistant mutants of FIV can arise as early as 6 months after the start of treatment.

\section{AMD3100}

AMD3100 belongs to the new class of bicyclams that act as selective antagonists of the chemokine receptor CXCR4. This molecule is the main co-receptor for $\mathrm{T}$ cell lineadapted HIV strains and, when blocked with AMD3100, virus entry is inhibited. Feline immunodeficiency virus also uses CXCR4 for virus entry. ${ }^{56,57}$ AMD3100 is not licensed as an antiviral compound but it is effective against FIV in vitro. In a placebo-controlled doubleblind study, in which naturally FIV-infected cats were treated $(0.5 \mathrm{mg} / \mathrm{kg}$ q12h SC for 6 weeks), the drug caused a statistically significant improvement in clinical signs and a decreased proviral load. Side effects were not noted [EBM grade I]. ${ }^{58}$

\section{Interferons}

Feline interferon-omega was recently licensed for veterinary use in some European countries and Japan. Interferons are antiviral, immunomodulatory and anti-tumour cytokines, which are species-specific; feline interferonomega can therefore be used for the duration of a cat's life without inducing antibody. Also, in contrast to the experience in human subjects, side effects have not been reported in cats. This cytokine is active against FIV in vitro, but in the only controlled study performed in field cats, no significantly improved survival rates were evident [EBM grade 1]. ${ }^{59}$

Human interferon-alpha induces an antiviral state in cells and also has immunomodulatory effects. ${ }^{60}$ Two treatment regimens have been published for the treatment of retroviral infections in cats [EBM grade III]. ${ }^{61,62}$ Whereas feline interferon-omega is available commercially and would be the appropriate cytokine to use, it is rather human interferon-alpha that 


\section{Vaccination}

There is no FIV vaccine commercially available in Europe. Experimentally, protection has been achieved by using several immunogens, including inactivated virus or infected cells, canarypox-based antigen expression in combination with inactivated cells and naked DNA. ${ }^{63}$ The most successful so far have been whole inactivated virus preparations; one such vaccine has been on the market in the USA since 2002

and in Australia and New Zealand since 2004.

However, this vaccine's efficacy has not been tested against challenge with European field isolates and did not protect cats against a virulent UK primary FIV isolate [EBM grade III]. ${ }^{64}$ Imported vaccinated cats might therefore not be protected against naturally occurring European isolates of FIV.
Not

recommended

The $A B C D$ does not recommend the use of the FIV vaccine in Europe, because it invalidates the serological diagnosis of infections and may not protect against European isolates.

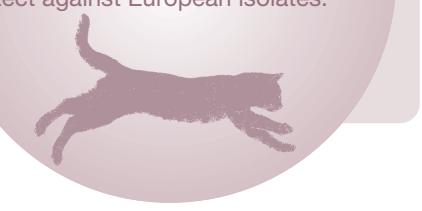

has been reported to prolong the survival times of FIV-infected cats [EBM III]. ${ }^{62}$

Immune modulators and interferon inducers Immune modulators and interferon inducers are widely used medications in FIV-infected cats. There is no conclusive evidence from controlled studies that they have any beneficial effects on health or survival. Rather, a non-specific immune stimulation can lead to increased viral loads via the activation of latently infected cells, and hence disease progression. These products should not be used in FIV-infected cats.

\section{Disease control in specific situations}

\section{Multi-cat households}

The risk of FIV transmission is low in households with socially well-adapted cats. If one cat is diagnosed with FIV infection, all cats in that household should be tested. The virus is transmitted mainly during biting and fighting, and if no aggression occurs due to the stability of social and territorial structures, the probability of transmission is low. In followup studies, few additional cats seroconverted over many years. All cats should be neutered, and no new cats introduced, as this might disrupt the harmony, even between cats that have lived peacefully together for a long time.

If other infectious diseases are spreading in a multi-cat community, the risk of FIV transmission may also be higher. In that situation, isolation of seropositive cats should be considered.

\section{Shelters}

Feline immunodeficiency virus is an important consideration in rescue shelters as the prevalence of infection is particularly high in populations with a feral background and in male cats. The prevalence may be lower in pre-owned cats that have recently been relinquished, compared with sheltered stray cats.

The ABCD recommends that all cats should be tested. If this cannot be achieved, at least all sick cats should be tested, and euthanasia considered when the clinical problems relate to an advanced stage of FIV infection.

Serological tests do not reliably identify infected kittens under 6 months of age. A positive result does not confirm that the kitten is infected and it must be emphasised that it is not an indication for euthanasia. In this situation, diagnosis by PCR may be considered.

The ABCD recommends that in rescue shelters, seropositive cats should be housed individually (unless from the same household); as an absolute minimum, FIV-positive cats should be segregated from FIV-negative cats. Some shelters will home FIV-positive healthy cats to selected adopters who offer living environments where the risk of infection for other cats is minimal. Detailed counselling is required.

\section{Breeding catteries}

Usually, cats in breeding catteries are kept indoors and are tested annually, and hence FIV is rare. New cats should be tested before being introduced, and breeders using an external stud or allowing an external queen to visit their stud should request proof of FIV-negative status. Cats that have escaped and returned should be quarantined for 3 months, tested and returned to their group only if found to be seronegative.

\section{Acknowledgements}

The European Advisory Board on Cat Diseases (ABCD) is indebted to Dr Karin de Lange for her judicious assistance in organising this special issue, her efforts at coordination, and her friendly deadline-keeping. The tireless editorial assistance of Christina Espert-Sanchez is gratefully acknowledged. The groundwork for this series of guidelines would not have been possible without financial support from Merial. The ABCD particularly appreciates the support of Dr Jean-Christophe Thibault, who respected the team's insistence on scientific independence.

\section{The risk of FIV transmission is low in multi-cat households with socially well-adapted cats.}




\section{POINTS}

First isolated in 1986, feline immunodeficiency virus (FIV) is a retrovirus closely related to human immunodeficiency virus. Most felids are susceptible to FIV, but humans are not.

\% FIV is endemic in domestic cat populations worldwide (subtypes A and B are most common in Europe).

Sick adult cats, male cats and free-roaming cats are most likely to be infected.

FIV loses infectivity quickly outside the host and is susceptible to all disinfectants including common soap.

4 Most FIV infections are acquired by bites (fights, mating) from persistently infected cats. The risk of transmission is low in households with socially well-adapted cats.

\# FIV infection has a long latent or 'asymptomatic' phase. Infected cats generally remain free of clinical signs for several years, and some cats never develop disease.

\$ Most clinical signs are not caused by FIV, but are the consequence of immunodeficiency.

* Positive in-practice ELISA results obtained in a low-prevalence or low-risk population should always be confirmed by a laboratory.

\$ PCR-based assays (for proviral DNA) are variable in performance and may even be inferior to serological tests.

Kittens from FIV-infected queens may test seropositive due to persisting maternal antibodies, and should be retested at 16 weeks of age.

* Cats should never be euthanased solely on the basis of an FIV-positive test result. FIV-infected cats may live as long as uninfected cats.

* Asymptomatic FIV-infected cats should be neutered to avoid bite incidents and virus transmission.

\$ Surgery is well tolerated by asymptomatic FIV-infected cats, but perioperative antibiotic treatment should be used in all cases.

At present there is no FIV vaccine commercially available in Europe.

Needles and surgical instruments used on FIV-positive cats may transmit the virus to other cats, so strict hygiene is essential.

\section{References}

1 Miller RJ, Cairns S, Bridges S, Sarver N. Human immunodeficiency virus and AIDS: insights from animal lentiviruses. J Virol 2000; 74: 7187-95.

2 Barr MC, Zou LL, Long F, Hoose WA, Avery RJ. Proviral organization and sequence analysis of feline immunodeficiency virus isolated from a pallas cat. Virology 1997; 228: 84-91.

3 Brown EW, Yuhki N, Packer C, O'Brien SJ. A lion lentivirus related to feline immunodeficiency virus - epidemiologic and phylogenetic aspects. J Virol 1994; 68: 5953-68.

4 Carpenter MA, Brown EW, Culver M, et al. Genetic and phylogenetic divergence of feline immunodeficiency virus in the puma (Puma concolor). J Virol 1996; 70: 6682-93.

5 Olmsted RA, Langley R, Roelke ME, et al. Worldwide prevalence of lentivirus infection in wild feline species: Epidemiologic and phylogenetic aspects. J Virol 1992; 66: 6008-18.

6 Olmsted RA, Hirsch VM, Purcell RH, Johnson PR. Nucleotide sequence analysis of feline immunodeficiency virus: genome organization and rela- tionship to other lentiviruses. Proc Natl Acad Sci USA 1989; 86: 8088-92.

7 Sodora DL, Schpaer EG, Kitchell BE, Dow SW, Hoover EA, Mullins JI. Identification of three feline immunodeficiency virus (FIV) env gene subtypes and comparison of the FIV and human immunodeficiency virus type 1 evolutionary patterns. J Virol 1994; 68: 2230-38.

8 Bachmann MH, Mathiason-Dubard C, Learn GH, et al. Genetic diversity of feline immunodeficiency virus: dual infection, recombination and distinct evolutionary rates among envelope sequence clades. J Virol 1997; 74: 4241-53.

9 Kann RK, Kyaw-Tanner MT, Seddon JM, Lehrbach PR, Zwijnenberg RJ, Meers J. Molecular subtyping of feline immunodeficiency virus from domestic cats in Australia. Aust Vet J 2006; 84: 112-16.

10 Pedersen NC, Ho EW, Brown ML, Yamamoto JK. Isolation of a T-lymphotropic virus from domestic cats with an immunodeficiency-like syndrome. Science 1987; 235: 790-93.

11 Hartmann K. Feline immunodeficiency virus infec- 
tion: an overview. Vet J 1998; 155: 123-37.

12 Hosie MJ, Robertson C, Jarrett O. Prevalence of feline leukaemia virus and antibodies to feline immunodeficiency virus in cats in the United Kingdom. Vet Rec 1989; 125: 293-97.

13 Yamamoto JK, Hansen H, Ho EW, et al. Epidemiologic and clinical aspects of feline immunodeficiency virus infection in cats from the Continental United States and Canada and possible mode of transmission. J Am Vet Med Assoc 1989; 194: 213-20.

14 O'Neil LL, Burkhard MJ, Diehl LJ, Hoover EA. Vertical transmission of feline immunodeficiency virus. AIDS Res Hum Retroviruses 1995; 11: 171-82.

15 O'Neil LL, Burkhard MJ, Hoover EA. Frequent perinatal transmission of feline immunodeficiency virus by chronically infected cats. J Virol 1996; 70: 2894-901.

16 Moench TR, Whaley KJ, Mandrell TD, Bishop BD, Witt CJ, Cone RA. The cat/feline immunodeficiency virus model for transmucosal transmission of AIDS: nonoxynol-9 contraceptive jelly blocks transmission by an infected cell inoculum. AIDS 1993; 7: 797-802.

17 Jordan HL, Howard J, Barr MC, Kennedy-Stoskopf S, Levy JK, Tompkins WA. Feline immunodeficiency virus is shed in semen from experimentally and naturally infected cats. AIDS Res Hum Retroviruses 1998; 14: 1087-92.

18 Shimojima M, Miyazawa T, Ikeda Y, et al. Use of CD134 as a primary receptor by the feline immunodeficiency virus. Science 2004; 303: 1192-95.

19 Willett BJ, McMonagle EL, Ridha S, Hosie MJ. Differential utilization of CD134 as a functional receptor by diverse strains of feline immunodeficiency virus. J Virol 2006; 80: 3386-94.

20 Torten M, Franchini M, Barlough JE, et al. Progressive immune dysfunction in cats experimentally infected with feline immunodeficiency virus. J Virol 1991; 65: 2225-30.

$21 \mathrm{Pu} \mathrm{R}$, Okada S, Little ER, Xu B, Stoffs WV, Yamamoto JK. Protection of neonatal kittens against feline immunodeficiency virus infection with passive maternal antiviral antibodies. AIDS 1995; 9: 235-42.

22 Siebelink KH, Tijhaar E, Huisman RC, et al. Enhancement of feline immunodeficiency virus infection after immunizaion with envelope glycoprotein subunit vaccines. J Virol 1995; 69: 3704-11.

23 Beatty JA, Willett BJ, Gault EA, Jarrett O. A longitudinal study of feline immunodeficiency virusspecific cytotoxic T lymphocytes in experimentally infected cats, using antigen-specific induction. J Virol 1996; 70: 6199-206.

24 Fevereiro M, Roneker C, Laufs A, Tavares L, de Noronha F. Characterization of two monoclonal antibodies against feline immunodeficiency virus gag gene products and their application in an assay to evaluate neutralizing antibody activity. J Gen Virol 1991; 72: 617-22.

25 Hosie MJ, Jarrett O. Serological responses of cats to feline immunodeficiency virus. AIDS 1990; 4: 215-20.
26 Rimmelzwaan GF, Siebelink KH, Broos H, et al. Gag and env-specific serum antibodies in cats after natural and experimental infection with feline immunodeficiency virus. Vet Microbiol 1994; 39: 153-65.

27 del Fierro GM, Meers J, Thomas J, Chadwick B, Park HS, Robinson WF. Quantification of lymphadenopathy in experimentally induced feline immunodeficiency virus infection in domestic cats. Vet Immunol Immunopathol 1995; 46: 3-12.

28 Pedersen NC, Yamamoto JK, Ishida T, Hansen H. Feline immunodeficiency virus infection. Vet Immunol Immunopathol 1989; 21: 111-29.

29 Ishida T, Taniguchi A, Matsumura S, Washizu T, Tomoda I. Long-term clinical observations on feline immunodeficiency virus infected asymptomatic carriers. Vet Immunol Immunopathol 1992; 35: $15-22$.

30 Addie DD, Dennis JM, Toth S, Callanan JJ, Reid S, Jarrett O. Long-term impact on a closed household of pet cats of natural infection with feline coronavirus, feline leukaemia virus and feline immunodeficiency virus. Vet Rec 2000; 146: 419-24.

31 Hughes MS, Ball NW, Love DN, et al. Disseminated Mycobacterium genavense infection in a FIV-positive cat. J Feline Med Surg 1999; 1: 23-9.

32 Pennisi MG. A high prevalence of feline leishmaniasis in southern Italy. Proceedings of the Second International Leishmaniasis Forum. Sevilla, Spain, 2002: 39-48.

33 Callanan JJ, Jones BA, Irvine J, Willett BJ, McCandlish IA, Jarrett O. Histologic classification and immunophenotype of lymphosarcomas in cats with naturally and experimentally acquired feline immunodeficiency virus infections. Vet Pathol 1996; 33: 264-72.

34 Tenorio AP, Franti CE, Madewell BR, Pedersen NC. Chronic oral infections of cats and their relationship to persistent oral carriage of feline calici-, immunodeficiency, or leukemia viruses. Vet Immunol Immunopathol 1991; 29: 1-14.

35 Ryan G, Grimes T, Brankin B, Mabruk MJ, Hosie MJ, Jarrett O, Callanan JJ. Neuropathology associated with feline immunodeficiency virus infection highlights prominent lymphocyte trafficking through both the blood-brain and blood-choroid plexus barriers. J Neurovirol 2005; 11: 337-45.

36 Kennedy JM, Hoke A, Zhu Y, et al. Peripheral neuropathy in lentivirus infection: evidence of inflammation and axonal injury. AIDS 2004; 18: 1241-50.

37 Phillips TR, Prospero-Garcia O, Wheeler DW, et al. Neurologic dysfunctions caused by a molecular clone of feline immunodeficiency virus, FIV-PPR. J Neurovirol 1996; 2: 388-96.

38 Weaver CC, Burgess SC, Nelson PD, et al. Placental immunopathology and pregnancy failure in the FIV-infected cat. Placenta 2005; 26: 138-47.

39 Poli A, Falcone ML, Bigalli L, et al. Circulating immune complexes and analysis of renal immune deposits in feline immunodeficiency virus-infected cats. Clin Exp Immunol 1995; 101: 254-58.

40 Matsumoto H, Takemura N, Sako T, Koyama H, 
Motoyoshi S, Inada Y. Serum concentration of circulating immune complexes in cats infected with feline immunodeficiency virus detected by immune adherence hemagglutination method. J Vet Med Sci 1997; 59: 395-96.

41 Pennisi MG, Masucci M, De Majo M. Presenza di anticorpi anti-nucleo in gatti FIV positivi. Proceedings of Società Italiana delle Scienze Veterinarie 1994; 48: 973-76.

42 Bienzle D, Reggeti F, Wen X, Little S, Hobson J, Kruth S. The variability of serological and molecular diagnosis of feline immunodeficiency virus infection. Can Vet J 2004; 45: 753-57.

43 Crawford PC, Levy JK. New challenges for the diagnosis of feline immunodeficiency virus infection. Vet Clin North Am Small Anim Pract 2007; 37: 335-50.

44 Dandekar S, Beebe AM, Barlough J, et al. Detection of feline immunodeficiency virus (FIV) nucleicacids in FIV-seronegative cats. J Virol 1992; 66: 4040-49.

45 Lutz H, Arnold P, Hübscher U, Egberink H, Pedersen NC, Horzinek MC. Specificity assessment of feline T-lymphotropic lentivirus serology. Zentralbl Veterinarmed B 1988; 35: 773-78.

46 Levy J, Richards J, Edwards D, et al. Report of the American Association of Feline Practitioners and Academy of Feline Medicine Advisory Panel on Feline Retrovirus Testing and Management. J Feline Med Surg 2003; 5: 3-10.

47 Richards JR. Feline immunodeficiency virus vaccine: implications for diagnostic testing and disease management. Biologicals 2005; 33: 215-17.

48 Lutz H, Egberink H, Arnold P, et al. Felines Tlymphotropes lentivirus (FTLV): experimentelle infektion und vorkommen in einigen Ländern Europas. Kleintierpraxis 1988; 33: 455-59.

49 Pedersen NC, Leutenegger CM, Woo J, Higgins J. Virulence differences between two field isolates of feline immunodeficiency virus (FIV-A Petaluma and FIV-CP Gammar) in young adult specific pathogen free cats. Vet Immunol Immunopathol 2001; 79: 53-67.

50 George JW, Pedersen NC, Higgins J. The effect of age on the course of experimental feline immunodeficiency virus infection in cats. AIDS Res Hum Retroviruses 1993; 9: 897-905.

51 Shelton GH, Grant CK, Linenberg ML, Abkowitz JL. Severe neutropenia associated with griseofulvin in cats with FIV infection. J Vet Intern Med 1990; 4: 317-19.

52 Phillips K, Arai M, Tanabe T, et al. FIV-infected cats respond to short-term $\mathrm{rHuG-CSF}$ treatment which results in anti-GCSF neutralizing antibody production that inactivates drug activity. Vet Immunol Immunopathol 2005; 108: 357-71.
53 Arai M, Darman J, Lewis A, Yamamoto JK. The use of human hematopoietic growth factors (rhGM-CSF and rhEPO) as a supportive therapy for FIV-infected cats. Vet Immunol Immunopathol 2000; 77: 71-92.

54 Woo JC, Dean GA, Lavoy A, Clark R, Moore PF. Investigation of recombinant human insulin-like growth factor type I in thymus regeneration in the acute stage of experimental FIV infection in juvenile cats. AIDS Res Hum Retroviruses 1999; 15: 1377-88.

55 Hartman K, Donath A, Kraft W. AZT in the treatment of feline immunodeficiency virus infection. Part 2. Feline Pract 1995; 6: 13-20.

56 Willett BJ, Hosie MJ, Neil JC, Turner JD, Hoxie JA. Common mechanism of infection by lentiviruses. Nature 1997; 385: 587.

57 Egberink HF, De Clercq E, Van Vliet AL, et al. Bicyclams, selective antagonists of the human chemokine receptor CXCR4, potently inhibit feline immunodeficiency virus replication. J Virol 1999; 73: 6346-52.

58 Hartmann K, Stengel S, Klein D, Egberink H, Balzarini J. Efficacy of the chemokine receptor inhibitor 1,1'-bis-1,4,8,11-tetraazacyclotetradekan against feline immunodeficiency virus infection [abstract]. Sixth International Feline Retrovirus Research Symposium. Amelia Island, USA, 2002: 26.

59 de Mari K, Maynard L, Sanquer A, Lebreux B, Eun HM. Therapeutic effects of recombinant feline interferon-omega on feline leukemia virus (FeLV)infected and FeLV/feline immunodeficiency virus (FIV)-coinfected symptomatic cats. J Vet Intern Med 2004; 18: 477-82.

60 Tompkins WA. Immunomodulation and therapeutic effects of the oral use of interferon-alpha: mechanism of action. J Interferon Cytokine Res 1999; 19: 817-28.

61 Zeidner NS, Myles MH, Mathiason-DuBard CK, Dreitz MJ, Mullins JI, Hoover EA. Alpha interferon (2b) in combination with zidovudine for the treatment of presymptomatic feline leukemia virusinduced immunodeficiency syndrome. Antimicrob Agents Chemother 1990; 34: 1749-56.

62 Pedretti E, Passeri B, Amadori M, et al. Low-dose interferon-alpha treatment for feline immunodeficiency virus infection. Vet Immunol Immunopathol 2006; 109: 245-54.

63 Hosie MJ, Beatty JA. Vaccine protection against feline immunodeficiency virus - setting the challenge. Aust Vet J 2007; 85: 5-12.

64 Dunham SP, Bruce J, MacKay S, Golder M, Jarrett $\mathrm{O}$, Neil JC. Limited efficacy of an inactivated feline immunodeficiency virus vaccine Vet Rec 2006; 158: 561-62. 